\title{
MDC0-700, a New Generation Anesthetic: Evaluation of Two Formulations in Sprague-Dawley Rats
}

\author{
Mojgan Sabet ${ }^{*}$, Ziad Tarazi, Nitin Joshi, Brad Zerler, Douglas E. Rains and David C. Griffith \\ The Medicines Company, 3013 Science Park Rd, San Diego, USA. CA 92121-1309.
}

Received: April 18 2018; Accepted: May 30 2018; Published: June 042018

*Corresponding author: Mojgan Sabet, The Medicines Company, 3013 Science Park Rd, San Diego, USA, CA 92121-1309. Tel: 858-875-6679;Fax: 858-875-2851;E-mail: mojgan.sabet@themedco.com

\begin{abstract}
Background: MDC0-700(cyclopropyl-methoxycarbonyl metomidate) is a novel, potent, positive allosteric modulator of the $\gamma$-Aminobutyric Acid type A $\left(\mathrm{GABA}_{\mathrm{A}}\right)$ receptor currently being developed for general anesthesia and procedural sedation. Early studies were conducted with a formulation that had to be stored at frozen conditions. A new formulation was developed to enable storage under refrigerated conditions. The original formulation (MDCO-700-F1) and the new formulation (MDC0-700-F2) were both prepared in Sulfobutyl ether- $\beta$-cyclodextrin (SBE $\beta C D$ ), however MDCO-700-F2 was prepared at a lower concentration and higher $\mathrm{pH}$ in order to improve long-term storage stability. The objective of this study was to compare the anesthetic effects of both formulations in male Sprague-Dawley rats.
\end{abstract}

Methods: Rats received doses of either MDCO-700-F1 or MDCO$700-\mathrm{F} 2$ ranging from 1 to $6 \mathrm{mg} / \mathrm{kg}$. Doses were administered as an intravenous bolus over 5 seconds via surgically implanted jugular vein cannulas. Immediately after the bolus, rats were turned supine and the clinical signs of anesthesia were monitored until they returned to normal behavior. The relationships between dose and the anesthetic effects of MDCO-700 were analyzed and modeled using pharmacodynamic models.

Results: Both formulations rapidly produced similar dosedependent depths of sedation with increasing effect at higher doses. The time required for recovery, as assessed using qualitative and semi-quantitative metrics, increased with increasing dose and was similar for the two formulations. The dose-response for all measured parameters including arousal level, duration of action and full recovery were similar for both formulations.

Conclusion: Under the conditions of this study, the data demonstrates that both formulations of MDCO-700 produced equivalent anesthetic effects in rats across the concentration range tested. These results suggest that either formulation can be used for ongoing clinical development.

Key words: MDC0-700; anesthetic; Sprague-Dawley rats;

\section{Introduction}

Etomidate, propofol, midazolam and thiopental are commonly used anesthetic and sedative agents that act by enhancing the function of $\gamma$-Aminobutyric Acid $\left(\mathrm{GABA}_{\mathrm{A}}\right)$ receptors in the central nervous system [1]. Among these four agents, propofol and etomidate are the most commonly used agents to induce anesthesia at the start of surgery. Etomidate is used as an anesthetic agent in emergency departments and intensive care units. It produces a rapid onset of anesthesia with minimum effects on both heart rate and blood pressure and, therefore, can be safely used in patients with valvular or ischemic heart disease [2]. Unfortunately, the suppression of adrenocortical function by etomidate has raised a major concern among clinicians [3].

Cyclopropyl-methoxycarbonyl metomidate, also known as MDCO-700, is currently being developed for general anesthesia and procedural sedation. It offers the promise of rapid onset and offset of anesthetic effects without a significant impact on respiration, hemodynamics or adrenocortical suppression. While MDCO-700 possesses these favorable pharmacologic properties, it is poorly soluble in water at $\mathrm{pH}$ greater than $\sim 2.5$ and is unstable in aqueous solution. Therefore, MDCO-700 is formulated using Sulfobutyl ether- $\beta$-cyclodextrin (SBE $\beta C D$ ) as a solubilizing agent. The initial formulation (MDCO-700-F1) was developed at a concentration of $10 \mathrm{mg} / \mathrm{ml}$ in $10 \%$ SBE $\beta C D$ at a $\mathrm{pH}$ of 3.0. However, this formulation had to be stored frozen at $-20^{\circ} \mathrm{C}$ for long term storage stability. To overcome this limitation, MDCO-700was reformulated at $4 \mathrm{mg} / \mathrm{mL}$ in $10 \%$ SBE $\beta C D$ at a $\mathrm{pH}$ of 5.5 (MDCO-700-F2). This new formulation offered the benefit of long term storage under refrigerated conditions instead of frozen at $-20^{\circ} \mathrm{C}$. A comparison of the formulations is provided in Table 1.

\begin{tabular}{|c|c|c|}
\hline Component & MDC0-700-F1 & MDC0-700-F2 \\
\hline MDCO-700 & $10 \mathrm{mg} / \mathrm{mL}$ & $4 \mathrm{mg} / \mathrm{mL}$ \\
\hline $\begin{array}{c}\text { Sulfobutyl ether- } \beta \text { - } \\
\text { cyclodextrin (SBE } \beta C D \text { ) }\end{array}$ & $100 \mathrm{mg} / \mathrm{mL}(10 \%)$ & $100 \mathrm{mg} / \mathrm{mL}(10 \%)$ \\
\hline Meglumine & $\begin{array}{l}\text { Added to adjust } \\
\text { pH to } 3\end{array}$ & Not used \\
\hline Citric Acid anhydrous & Not used & $0.55 \mathrm{mg} / \mathrm{mL}$ \\
\hline Sodium Citrate & Not used & $1.84 \mathrm{mg} / \mathrm{mL}$ \\
\hline Sodium Hydroxide & Not used & $\begin{array}{c}\text { Added to adjust } \mathrm{pH} \\
\text { to } 5.5\end{array}$ \\
\hline
\end{tabular}


The objective of this study was to compare the anesthetic effects of these two formulations of MDCO-700 in male SpragueDawley rats.

\section{Materials and Methods}

\section{Animals}

All animal studies were performed under a protocol approved by an Institutional Animal Care and Use Committee (IACUC). Male Sprague-Dawley rats (Envigo Laboratories, Indianapolis, IN), weighing between 300-350 grams, had jugular vein cannulas (JVC) surgically implanted by the vendor prior to receipt. Upon receipt, the animals were individually housed in a room with a controlled environment and acclimated to laboratory conditions for at least 24 hours prior to the start of dosing. Animals were provided food and water ad libitum. Throughout all procedures, animals were kept warm using heating pads to avoid hypothermia. During the experiment, animals were manually restrained to prepare the cannula, after which they were free to move during and following administration of the dose.

\section{Treatment}

MDC0-700-F1 was manufactured by The Medicines Company and was stored frozen at $-20^{\circ} \mathrm{C}$ until use. MDC0-700-F2 was manufactured by The Medicines Company and was kept refrigerated until use. Prior to dosing, each formulation was brought to room temperature approximately 30 minutes prior to administration.

\section{Dosing}

After acclimation, male rats were randomized $(n=4)$ to one of 10 treatment groups. Rats received 1,2,3,4 or $6 \mathrm{mg} /$ $\mathrm{kg}$ of either MDCO-700-F1 or MDCO-700-F2 (Table 2). Each dose was administered by intravenous bolus over 5 seconds via the JVC using an insulin syringe (EXEL INT, Redondo Beach, CA) affixed with a blunt needle. The total time of dosing was carefully controlled to be 5 seconds to ensure equipotent dosing $(\mathrm{mg} / \mathrm{kg} / \mathrm{min})$ between the two formulations.

\begin{tabular}{|c|c|c|c|c|c|}
\hline Group & Compound & $\begin{array}{c}\text { Conc. } \\
(\mathrm{mg} / \mathrm{ml})\end{array}$ & \# of Animals & $\begin{array}{c}\text { Dose } \\
\text { (mg/kg) }\end{array}$ & $\begin{array}{c}\text { Dose Volume } \\
\text { (mL/kg) }\end{array}$ \\
\hline 1 & MDC0-700-F1 & 10 & 4 & 1 & 0.10 \\
\hline 2 & MDC0-700-F1 & 10 & 4 & 2 & 0.20 \\
\hline 3 & MDC0-700-F1 & 10 & 4 & 3 & 0.30 \\
\hline 4 & MDC0-700-F1 & 10 & 4 & 4 & 0.40 \\
\hline 5 & MDC0-700-F1 & 10 & 4 & 6 & 0.60 \\
\hline 6 & MDCO-700-F2 & 4 & 4 & 1 & 0.25 \\
\hline 7 & MDCO-700-F2 & 4 & 4 & 2 & 0.50 \\
\hline 8 & MDCO-700-F2 & 4 & 4 & 3 & 0.75 \\
\hline 10 & MDCO-700-F2 & 4 & 4 & 6 & 1.50 \\
\hline
\end{tabular}

Pharmacodynamic Measures: Clinical Signs of displays exploratory behavior).

\section{Anesthesia}

Immediately after the dose, rats were turned supine, and the following clinical signs were monitored and recorded for all animals: a) arousal level, b) time to emergence from anesthesia, c) time to sternal recumbency, d) time to recovery from loss of righting reflex (LORR) and e) time to return to normal (alert and
Arousal level was scored using a subjective numerical anesthesia scale (Table 3). The arousal level was scored between 1 (deeply unconscious and sedated) to a score of 5 (but sluggish and not fully normal). In some animals, the arousal level was between 1 and 2 because rats were not deeply anesthetized but appeared sedated. These data were reported at 1.5.

Table 3: Behavioral signs associated with Arousal level

\begin{tabular}{|c|l|}
\hline Arousal Level & \\
\hline 1 & Animal appears unconscious \\
\hline 2 & Animal appears sedated but not unconscious \\
\hline 3 & Animal appears sedated and responds to environmental stimuli \\
\hline 4 & Animal appears sedated and exhibits signs of excitation such as involuntary movements \\
\hline 5 & Animal is not sedated but slow and sluggish with some exploratory behavior with periods of inactivity \\
\hline
\end{tabular}


The duration of effect was subcategorized to time to emergence (head up and turning around), time to sternal recumbency (only front paws on ground), time to recovery from LORR (the animal turning and supporting weight with all 4 paws on ground) and finally, time to return to normal or full recovery from anesthesia.

\section{Pharmacodynamic Modeling}

The relationship between the dose and arousal level was fit to an inhibitory effect sigmoid Emax model (Phoenix $®$ WinNonlin $₫$ v 6.3, Certara, Mountain View, CA) as follows:

Arousal level $=\mathrm{E} 0-\left(\mathrm{I}_{\max } * \mathrm{X} \gamma\right) /\left(\mathrm{X} \gamma+\mathrm{IC}_{50} \gamma\right)$

where $\mathrm{E} 0$ is the effect when $\mathrm{X}$ is equal to zero, Imax is the maximum effect on arousal level, $\mathrm{X}$ is the dose, $\mathrm{EC}_{50}$ is the dose (X) corresponding to $50 \%$ of the maximum effect and $\gamma$ is the sigmoidicity factor which controls the steepness of the curve.

The relationship between duration of anesthetic effects and dose was fit using a sigmoid Emax model (Phoenix $₫$ WinNonlin ${ }^{\circledR}$ v 6.3, Certara, Mountain View, CA) as follows:

$$
\mathrm{E}=\left(\mathrm{E}_{\max } * \mathrm{X} \gamma\right) /\left(\mathrm{X} \gamma+\mathrm{EC}_{50} \gamma\right)
$$

where $\mathrm{E}$ is the duration of anesthetic effect (emergence from anesthesia, sternal recumbency, recovery of LORR, return to normal), $\mathrm{E}_{\max }$ is the maximum duration of anesthetic effect, $\mathrm{X}$ is the dose, $\mathrm{EC}_{50}$ is the dose $(\mathrm{X})$ corresponding to $50 \%$ of the maximum effect and $\gamma$ is the sigmoidicity factor which controls the steepness of the curve.

\section{Statistical Analysis}

The anesthetic effects of both MDCO-700 formulations were compared by unpaired t-test (Graph Pad Prism version 6.03), respectively. A p value of $<0.05$ was considered statistically significant.

\section{Results}

Clinical signs of anesthesia for both formulations are shown in Tables 4 and 5. With the exception of one rat, a dose of $1 \mathrm{mg} /$ $\mathrm{kg}$ did not produce any sedative effects with either formulation. Animals in this group looked sluggish and with periods of inactivity and losing balance, taking an average of 3 to 4 minutes to make a full recovery. At a dose of $2 \mathrm{mg} / \mathrm{kg}$, arousal levels were $3.5 \pm 1.0$ and $4.0 \pm 0.0$ while the times for recovery from LORR were $3.5 \pm 0.2$ and $4.5 \pm 0.7$ minutes for MDCO-700-F1 and MDCO$700-\mathrm{F} 2$, respectively. Time of emergence was an average of 2.7 minutes, the time to sternal recumbency was about 3 minutes, and all animals exhibited a full recovery 6 minutes after the injection for both formulations.

Table 4: Assessment of sedative effects and duration of action after a single intravenous bolus dose of MDCO-700-F1. The parameters are reported as mean $\pm \mathrm{SD}$

\begin{tabular}{|c|c|c|c|c|c|}
\hline $\begin{array}{c}\text { Dose } \\
\mathbf{( m g} / \mathbf{k g})\end{array}$ & $\begin{array}{c}\text { Arousal Level } \\
\mathbf{( 1 - 5 )}\end{array}$ & $\begin{array}{c}\text { Time to } \\
\text { Emergence } \\
\mathbf{( m i n )}\end{array}$ & $\begin{array}{c}\text { Time to Sternal } \\
\text { Recumbency } \\
\text { (min) }\end{array}$ & $\begin{array}{c}\text { Time to Recover } \\
\text { Righting Reflex } \\
\text { (min) }\end{array}$ & $\begin{array}{c}\text { Time to Return to } \\
\text { Normal } \\
\text { (min) }\end{array}$ \\
\hline 1 & $5.0 \pm 0.0$ & $0.0 \pm 0.0$ & $1.2 \pm 1.4$ & $1.4 \pm 1.6$ & $4.3 \pm 0.2$ \\
\hline 2 & $3.5 \pm 1.0$ & $2.7 \pm 0.6$ & $3.2 \pm 1.4$ & $3.5 \pm 0.2$ & $5.7 \pm 0.7$ \\
\hline 3 & $1.5 \pm 0.0$ & $4.4 \pm 1.3$ & $5.4 \pm 1.4$ & $5.4 \pm 1.4$ & $9.7 \pm 1.1$ \\
\hline 4 & $1.0 \pm 0.0$ & $5.1 \pm 1.0$ & $5.2 \pm 0.9$ & $5.5 \pm 0.7$ & $8.3 \pm 0.3$ \\
\hline 6 & $1.0 \pm 0.0$ & $5.7 \pm 0.4$ & $6.1 \pm 0.5$ & $6.8 \pm 0.5$ & $10.1 \pm 1.3$ \\
\hline
\end{tabular}

Table 5: Assessment of sedative effects and duration of action after a single intravenous bolus dose of MDCO-700-F2. The parameters are reported as mean $\pm \mathrm{SD}$.

\begin{tabular}{|c|c|c|c|c|c|}
\hline $\begin{array}{c}\text { Dose } \\
\mathbf{( m g} / \mathbf{k g})\end{array}$ & $\begin{array}{c}\text { Arousal Level } \\
\mathbf{( 1 - 5 )}\end{array}$ & $\begin{array}{c}\text { Time to } \\
\text { Emergence } \\
\mathbf{( m i n )}\end{array}$ & $\begin{array}{c}\text { Time to Sternal } \\
\text { Recumbency } \\
\text { (min) }\end{array}$ & $\begin{array}{c}\text { Time to Recover } \\
\text { Righting Reflex } \\
\text { (min) }\end{array}$ & $\begin{array}{c}\text { Time to Return to } \\
\text { Normal } \\
\text { (min) }\end{array}$ \\
\hline 1 & $4.8 \pm 0.5$ & $0.4 \pm 0.8$ & $0.5 \pm 1.6$ & $0.8 \pm 1.7$ & $2.7 \pm 1.2$ \\
\hline 2 & $4.0 \pm 0.0$ & $2.7 \pm 0.3$ & $3.3 \pm 0.7$ & $4.5 \pm 0.7$ & $5.9 \pm 0.9$ \\
\hline 3 & $1.5 \pm 0.0$ & $3.9 \pm 0.2$ & $4.6 \pm 0.2$ & $5.4 \pm 0.2$ & $8.4 \pm 0.9$ \\
\hline 4 & $1.0 \pm 0.0$ & $6.2 \pm 0.3$ & $6.2 \pm 0.3$ & $6.6 \pm 0.5$ & $8.7 \pm 0.3$ \\
\hline 6 & $1.0 \pm 0.0$ & $6.6 \pm 0.8$ & $6.7 \pm 0.8$ & $7.6 \pm 1.0$ & $10.3 \pm 1.2$ \\
\hline
\end{tabular}


At a dose of $3 \mathrm{mg} / \mathrm{kg}$, the average arousal levels were 1.5 for both formulations. The average time to emergence was 4.4 and 3.9 minutes for MDCO-700-F1 and MDCO-700-F2, respectively. The average time to sternal recumbency and recovery from LORR were 5.0 and 5.4 minutes, respectively. Compared to doses of 1 and $2 \mathrm{mg} / \mathrm{kg}$, times to emergence, sternal recumbency, and recovery from LORR were significantly increased for both formulations at the $3 \mathrm{mg} / \mathrm{kg}$ dose $(\mathrm{p}<0.0001)$.

Maximum sedative effects and duration of action were observed at doses of 4 and $6 \mathrm{mg} / \mathrm{kg}$ for both formulations. Animals were fully unconscious with a time to emergence of roughly, 6 minutes. There was no significant difference in time to emergence between the doses ( $p=0.155$ to 0.748 ). At the $4 \mathrm{mg} /$ $\mathrm{kg}$ dose, the time required for full recovery averaged 8.5 minutes for both formulations. At $6 \mathrm{mg} / \mathrm{kg}$, the time to full recovery for both formulations was 10 minutes which is significantly greater than that observed at $4 \mathrm{mg} / \mathrm{kg}(\mathrm{p}=0.025)$.

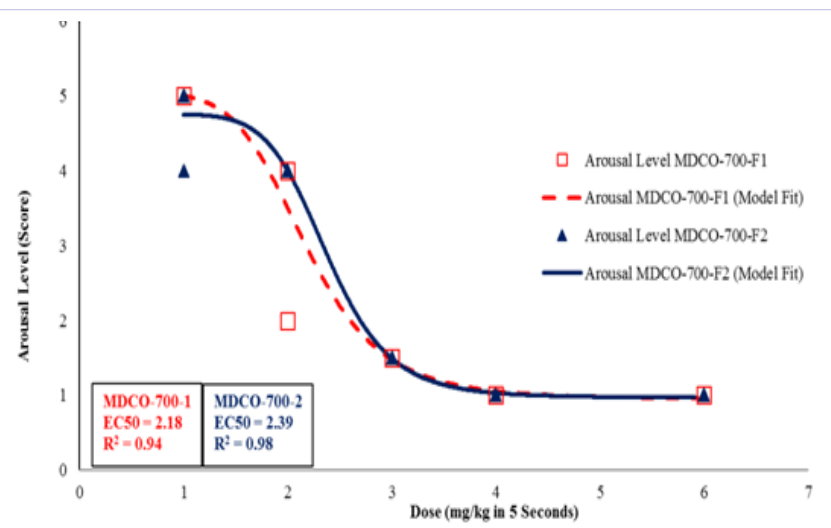

Figure 1: Relationship between dose and arousal level after intravenous bolus of MDCO-700.

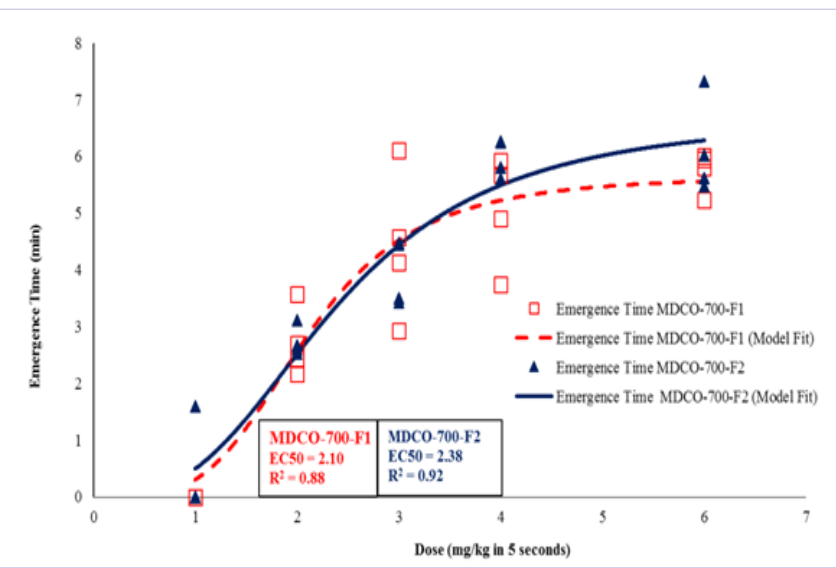

Figure 2: Relationships between dose and duration of action after an intravenous bolus of MDCO-700 in Sprague-Dawley rats.

Figure 2A: Time to emergence.

The relationship between the dose and arousal level for both formulations are shown in Fig 1. Arousal levels were dose-dependent with a maximum level at $4 \mathrm{mg} / \mathrm{kg}$ for both formulations. There was no significant difference in the arousal

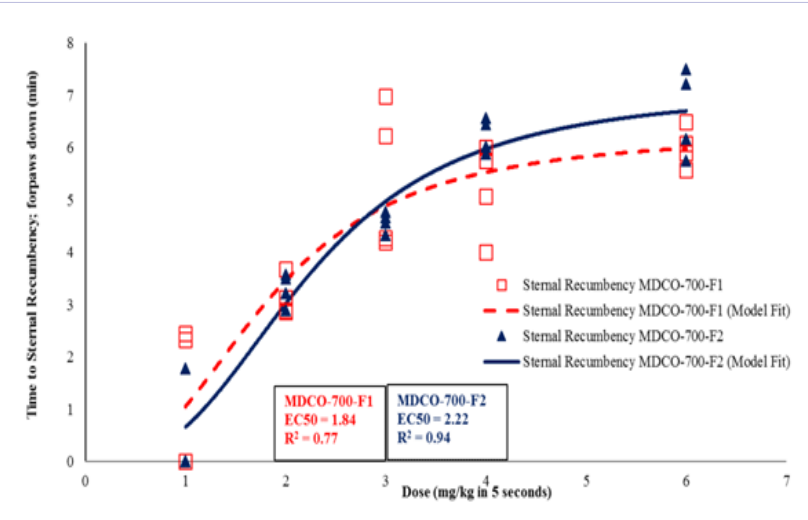

Figure 2B: Time to sternal recumbency.

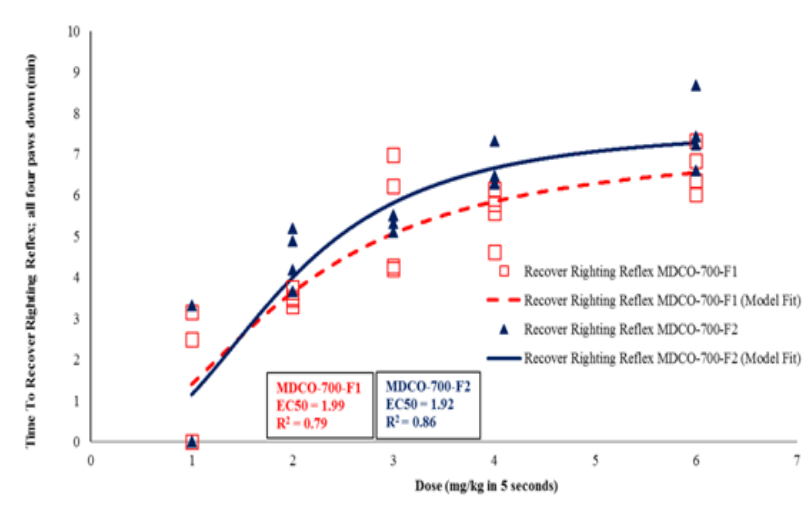

Figure 2C: Time to recover from LORR.

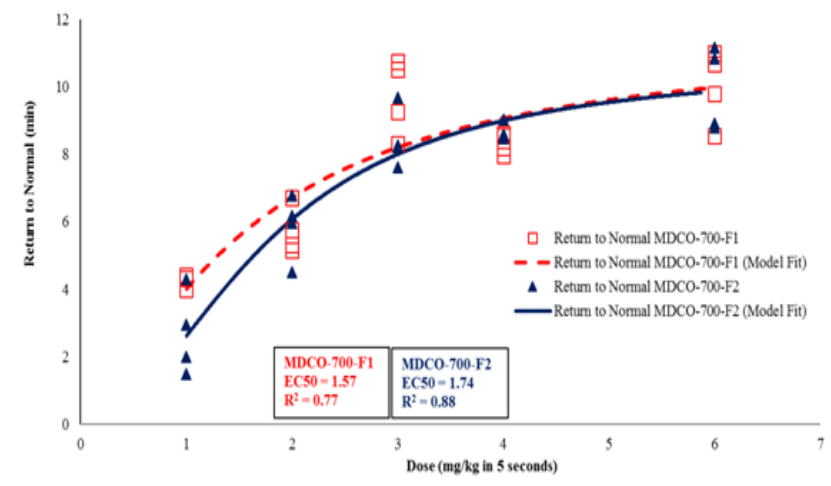

Figure 2D: Time to full recovery

level ( $p>0.05$ ) between the two formulations across the dosing range tested. As shown in Table 6, the calculated values for $50 \%$ of maximal effect (EC50) for arousal level were 2.39 and 2.18 for MDCO-700-F2 and MDCO-700-F1, respectively. The EC50 values for time to emergence, time to sternal recumbency, time to recovery from LORR and full recovery were similar for both formulations (Table 6). Overall, both formulations produced equivalent anesthetic effects and times to recovery. 
Table 6: The $50 \%$ of maximal effect $\left(\mathrm{EC}_{50}\right)$ values for arousal level, time to emergence, time to Sternal recumbency, time to recovery of LORR and time to normal after a bolus of MDCO-700-F1 or MDCO-700-F2

\begin{tabular}{|c|c|c|}
\hline \multirow{2}{*}{ Parameter } & \multicolumn{2}{|c|}{$\mathbf{E C}_{50}$} \\
\hline & MDC0-700-F1 & MDC0-700-F2 \\
\hline Arousal Level (1-5) & 2.18 & 2.39 \\
\hline Time to Emergence (min) & 2.10 & 2.38 \\
\hline Time to Sternal Recumbency (min) & 1.84 & 2.22 \\
\hline Time to Recover Righting Reflex (min) & 1.99 & 1.92 \\
\hline Time to Return to Normal (min) & 1.57 & 1.74 \\
\hline
\end{tabular}

\section{Discussion}

Etomidate was introduced in 1972 for the induction and maintenance of anesthesia due to its rapid sedative-hypnotic effect. Despite minimal hemodynamic changes or respiratory depression, its clinical utility is limited due adrenal toxicity associated with long infusions. MDCO-700 (cyclopropylmethoxycarbonyl metomidate) displays rapid sedative-hypnotic effects like etomidate, but with minimal adrenocortical suppression and as such, is a good candidate for further development [4].

As MDCO-700 was found to be relatively unstable in an aqueous solution, MDCO-700-F1 $(10 \mathrm{mg} / \mathrm{ml}$ concentration formulated in $10 \%$ SBE $\beta C D$ at a $\mathrm{pH}$ of 3.0) was developed and used for early Phase 1 clinical trials. While the formulation was stable, it required storage at $-20^{\circ} \mathrm{C}$ which is less than ideal for a commercial product. MDCO-700-F2 was developed in order to address this liability. MDCO-700-F2 is formulated at $4 \mathrm{mg} / \mathrm{mL}$ in $10 \%$ SBE $\beta C D$ at a $\mathrm{pH}$ of 5.5. These changes in the formulation maintain overall product stability while allowing for storage under refrigerated conditions $\left(2-8^{\circ} \mathrm{C}\right)$ instead of frozen at $-20^{\circ} \mathrm{C}$.
Our study was designed to compare the anesthetic effects and time to recovery for these two formulations in Sprague-Dawley rats. The data from this study demonstrate that both formulations produced equivalent depth of anesthesia (arousal level), time to emergence from anesthesia, time to sternal recumbency, time to recover from loss of righting reflex, and time to return to normal. Based on these results, further clinical development with the new formulation, MDCO-700-F2, is warranted.

\section{References}

1. Ge R, Pejo E, Gallin H, Jeffrey S, Cotten JF and Raines DE. The pharmacology of cyclopropyl-methoxycarbonyl metomidate: a comparison with propofol. Anesth Analg. 2014;118(3):563-567. Doi: 10.1213/ANE.0000000000000069.

2. Forman SA. Clinical and molecular pharmacology of etomidate. Anesthesiology . 2011;114(3):695-707. Doi:10.1097/ ALN.0b013e3181ff72b5.

3. Allolio B, Stuttmann R, Leonhard U, Fischer H and Winkelmann W. Adrenocortical suppression by a single induction dose of etomidate. Klin Wochenschr. 1984;62(21):1014-1017.

4. Campagna JA, Pojasek K, Grayzel D, Randle Jand Raines DE. Advancing novel anesthetics: pharmacodynamic and pharmacokinetic studies of cyclopropyl-methoxycarbonyl metomidate in dogs. Anesthesiology. 2014;121(6):1203-1216. Doi: 10.1097/ALN.0000000000000416. 